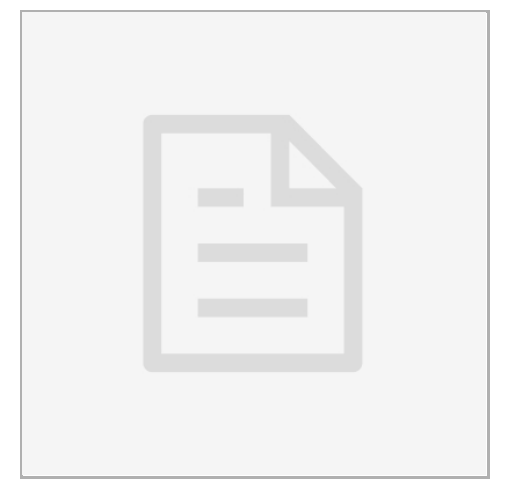

VERSION 1

FEB 05, 2020

open 2 access

DOI:

dx.doi.org/10.17504/protocol s.io.bbx3ipqn

Protocol Citation: Allen Institute for Brain Science 2020. Slide Preparation for Mounting Samples for TissueCyte 1000 Sectioning and Imaging. protocols.io https://dx.doi.org/10.17504/p rotocols.io.bbx3ipqn

License: This is an open access protocol distributed under the terms of the Creative Commons Attribution License, which permits unrestricted use, distribution, and reproduction in any medium, provided the original author and source are credited

Protocol status: Working We use this protocol and it's working

Created: Jan 29, 2020

Last Modified: Feb 05, 2020

PROTOCOL integer ID:

32475

\section{(3) Slide Preparation for Mounting Samples for TissueCyte 1000 Sectioning and Imaging V.1}

Allen Institute for Brain

Science ${ }^{1}$

${ }^{1}$ Allen Institute

\section{BICCN Allen Institute for Brain Science}

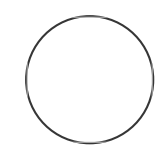

Dillan Brown

\section{ABSTRACT}

This protocol describes the preparation of $1 \times 3$ glass slides for mounting embedded mouse brain samples for subsequent imaging and sectioning on TissueCyte 1000 .

\section{ATTACHMENTS}

PF0260_TissueCyte_slide _preparation.docx 
Keywords: TissueCyte,

Sectioning, Mounting,

Imaging 